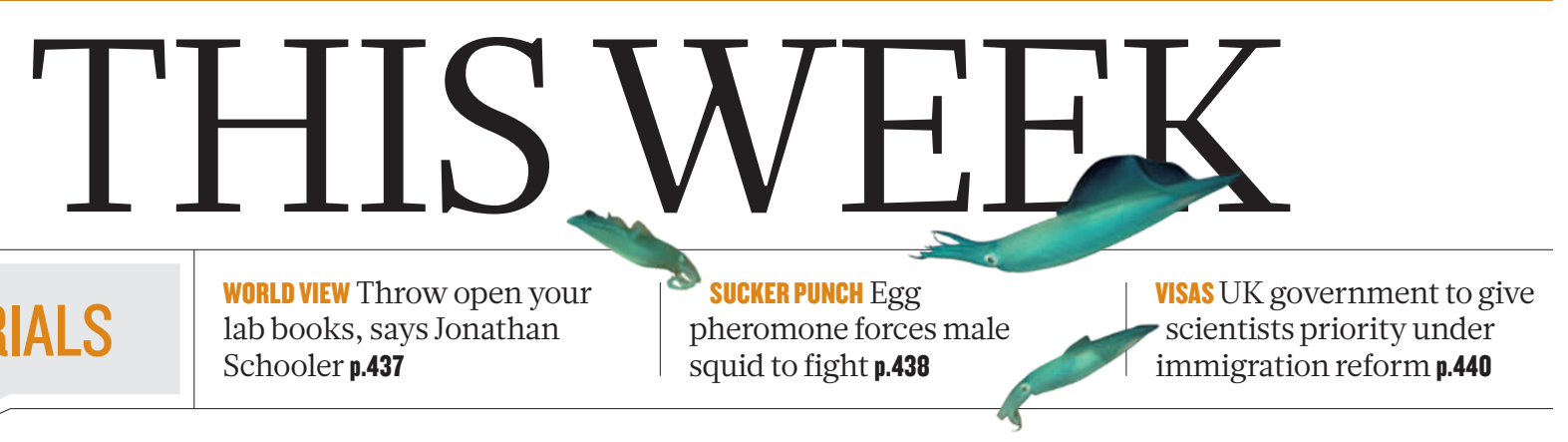

Animal rights and wrongs

\author{
A Nature survey shows the pernicious impact of activism on biomedical scientists. More \\ institutions must offer researchers the training they need to stand up for their work.
}

$\mathrm{T}$ The results of a Nature poll of scientists involved in animal research reveal that nearly one-quarter of respondents have been negatively affected by animal-rights activists, or seen it happen to someone they know. In some places, including the United Kingdom, the figure is higher than one-third. The large number of people affected will surprise many of Nature's readers. Researchers have suffered fire bombings, physical attacks, destruction of personal property and campaigns of harassment. But the statistics do not necessarily reflect the current prevalence of violent activist behaviour - rather, they reveal how such activity instils a lingering fear that is difficult to forget (see page 452).

The survey shows how corrosive animal-rights extremism can be. It is clear that many of those who perpetrate it remain unrepentant and determined to continue their efforts to terrorize researchers, but there are positive signs. Little more than $15 \%$ of poll respondents who were affected by activism said the tactics drove them to change the direction or practice of their research, and several who did make changes said that they mostly became more selective about who they talked to or how they presented their work on the Internet.

There are welcome signs that the tide of violent activity may be turning, especially in the United Kingdom. Several factors could be at work. Tougher legislation might be having an effect; in the past few years, Britain and the United States have both introduced laws that reinforce the seriousness of acts of vandalism intended to bully and blackmail those connected to animal research. Groups in favour of such research have also helped to calm the violence. Pro-Test, an organization based in Oxford, UK, which this week celebrates its fifth anniversary, has managed to counter a campaign of misinformation and intimidation that almost scuttled plans to build a biomedical research facility at the University of Oxford (see page 457). Other groups have begun to follow Pro-Test's lead, including an offshoot at the University of California, Los Angeles, which has been repeatedly targeted by activists. Proactive campaigns and pressure on lawmakers to protect the public's investment in research have aided the backlash against extremism. But these are only part of the solution.

Scientists regularly face the dilemma of how open to be about their animal research. Non-disclosure, even in the scientific literature, is common, according to a recent survey by the UK National Centre for the Replacement, Refinement and Reduction of Animals in Research. Such a lack of openness, it added, could impede reproduction and replication of previous work (C. Kilkenny et al. PLoS ONE 4, e7824; 2009). Findings such as these have led many journals, including Nature, to adopt more-explicit rules about what is to be reported in the literature (see go.nature.com/5zbqp4).

Talking to the public remains crucial. Sometimes, the threat of violence means that individual researchers will not wish to engage directly with the public and should even be cautioned against doing so. But there is no excuse for institutions that house animal research - including most research universities - not to have vigorous and well-defined programmes to explain what goes on within their walls. Institutions should publicize the high standards that they are required to meet before they can use animals. They should also discuss their strategies to replace animals with more sophisticated
"There is no excuse for institutions not to explain what goes on within their walls." reduce the overall number of animals used. If they have no such strategies, institutions should develop them as a priority.

Some scientists who work with animals are already willing to explain the importance of their research. Others should follow their lead. Nature's survey found that more than $50 \%$ of researchers were encouraged by their institutions to engage with the public, yet not much more than one-quarter felt they were given the necessary training or support. This is unacceptable: the resources are out there, including tips on how to communicate effectively and how best to respond to personal threats.

Activists often attempt to marginalize researchers, isolating them from their institutions and the wider community. If researchers build better and stronger bonds with both, they can ensure that it is the extremists who are marginalized. research tools, refine research practice and

\section{On the rebound}

\author{
A critical report has fuelled arguments about \\ the benefits of energy efficiency.
}

$\mathrm{T}$ The ghost of William Jevons has haunted energy researchers in recent months, provoking debates on whether our best efforts to use less energy will merely lead us farther down the road of consumption. Jevons, a British economist, suggested in 1865 that increasing energy efficiency could backfire because it would allow further resource exploitation. He was thinking about coal at the time. And, indeed, as people got better at converting this black rock's energy into useful work, the work itself expanded.

The 'Jevons paradox' has persisted ever since. Today, the notion that there could be some modest 'rebound' effect that negates gains in energy efficiency is well known. For example, drivers of fuel-efficient vehicles might be inclined to drive more often, simply because they can afford to do so. It takes energy to create and install energy-efficient equipment; and money saved on energy could be spent elsewhere, so ultimately contributing to economic activity, which drives up energy consumption and greenhouse-gas emissions. (Indeed, one reason for 